Section Editor

John J. Millichap, MD

Altaf Saadi, MD

Farrah J. Mateen, $\mathrm{MD}, \mathrm{PhD}$

Correspondence to Dr. Saadi: asaadi@partners.org

International Issues:

\title{
Teleneurology in humanitarian crises
}

\author{
Lessons from the Médecins Sans Frontières experience
}

ABSTRACT

Humanitarian emergencies defined by armed conflict, political strife, famine, or natural disaster can devastate populations rapidly. Neurologic disorders accompany these complex humanitarian emergencies but often go unheeded, exacerbated by a scarcity of neurologists. Teleneurology offers the promise of neurologic care remotely in the face of this inadequate local clinician supply. We describe our experiences as voluntary neurology teleconsultants with Médecins Sans Frontières in order to highlight both the promises and challenges of teleneurology in humanitarian contexts. We identified the major advantages of this service as (1) minimal resources and incurred costs while (2) changing a patient's clinical course favorably, and (3) creating a community for the field referrer and neurology specialist. Current challenges include (1) limited diagnostic resources and difficult diagnostic and therapeutic decision-making, (2) need for greater continuity and familiarity between the field site and neurologist, (3) gaps in the US neurology curriculum to provide expertise for all sites, (4) lack of follow-up and feedback from the field to advise future cases, and (5) low frequency of consultations. Growth opportunities include eventual expansion to the development of a community of neurologists who can provide context-specific care and maximize use of multimedia at low Internet bandwidth. Lessons from our experience may help optimize teleneurology's effect and reduce disparities in neurologic care, particularly in humanitarian crises. Neurology ${ }^{\circledR}$ 2017;89:e16-e19

\section{GLOSSARY}

AED = antiepileptic drug; MSF = Médecins Sans Frontières; $\mathbf{T B I}=$ traumatic brain injury

Humanitarian crises present distinct challenges for the provision of neurologic care, but provide opportunities to implement innovative technologies across traditional boundaries. In settings of armed conflict, famine, political strife, natural disaster, or a combination of these devastating situations, neurologists are generally absent. ${ }^{1}$ In some cases, there were never neurologists in these locations: in low-income countries in general, there is an estimated average of 3 neurologists per 10 million people, compared to high-income countries, where the same number exists for 100,000 people, a 100 -fold difference. ${ }^{2}$ In subSaharan African in particular, there is an estimated 0.6 neurologists per million people. ${ }^{3}$ In other situations, health care workers flee in times of emergency or are targeted. ${ }^{4}$ Meanwhile, the number of people who can access mobile devices and some form of Internet is increasing rapidly, especially in new locations across Asia, Africa, and the Middle East. ${ }^{5}$ Innovative solutions are almost certainly needed to facilitate access for neurologists in humanitarian emergencies, using newer technologies that have the potential to improve the lives of patients with neurologic disorders.

Over the last 2 years, we have voluntarily provided teleneurology consultations with Médecins Sans Frontières (MSF), a medical humanitarian emergency nonprofit organization that has 450 projects in 69 countries in addition to their search and rescue operations. ${ }^{5}$ From this experience, we have been able to identify some potential pitfalls and challenges in developing and using teleneurology in the context of humanitarian crises. Teleneurology can serve a meaningful role in the provision of neurologic care in the face of a limited clinician supply, and we hope lessons from our experience will be valuable for future efforts by organizations engaged with public health and neurology.

THE PROMISE OF TELEMEDICINE/TELENEUROLOGY Telemedicine is a burgeoning technology that allows the exchange of medical information between health care practitioners from

From Partners Neurology Residency (A.S.), Massachusetts General Hospital (F.J.M.) and Brigham and Woman's Hospital; and Harvard Medical School (F.J.M.), Boston, MA.

Go to Neurology.org for full disclosures. Funding information and disclosures deemed relevant by the authors, if any, are provided at the end of the article. 
disparate geographic areas to assist in patient diagnosis and treatment. The American telemedicine market is projected to grow $20 \%-50 \%$ annually, reaching a $\$ 30$ billion USD industry by $2019 .{ }^{6}$ Currently, telemedicine services are used by nearly $50 \%$ of acute care hospitals. $^{7,8}$

Telemedicine can take on many forms. For example, teleconsultations can occur in a synchronous or asynchronous manner. Synchronous telemedicine enables real-time communication. Asynchronous telemedicine features delayed communication, with data transmitted electronically and reviewed by patients or health care practitioners at a later time. This is also known as a store-and-forward system of telehealth consultation.

Teleneurology is a branch of telemedicine that allows consults and practices through remote neurologic evaluation, and has seen similar growth. ${ }^{9}$ It is often touted as a potential solution to the growing demand for neurologic services that outmatches the supply of neurologists, ${ }^{10}$ a demand which exists both domestically and globally.

BRIEF OVERVIEW OF MSF SYSTEM AND CASES In 2010, MSF launched a telemedicine project using store-and-forward methods based on the Collegium Telemedicus platform. ${ }^{11}$ This web-based messaging system provides doctors at its field sites with access to a wide range of specialists, including neurologists. Specialists provide purely advisory consultations, with the final patient management decisions remaining with physicians in the field. Correspondences are stored securely on the telemedicine server for ease of future reference. To date, more than 150 consults have been provided by $>10$ neurologists living in 6 countries. Physicians in the telemedicine consultant service must have an active medical license and are recruited through professional connections and recognized experience in field settings overseas. The neurology consultants collectively speak English, French, and Spanish, and there are translation services available if the referrer's questions are in an alternative language. The consultant group includes 3 pediatric neurologists.

PROMISES AND OPPORTUNITIES The potential benefits of teleneurology in humanitarian crises involve the provider on the ground, the neurologist remotely, and the patient.

Minimal resources and costs incurred. The infrastructure required for both the clinical referrer and neurologist to access this service is minimal-a computer and Internet access. There are no extra computer programs or software since the telemedicine system is accessed through a web browser. Given the storeand-forward approach, a constant Internet connection is not even required. Internet connection can be established for a temporary period of time in order to access and relay the necessary information. The dramatic growth of global mobile subscriptions, including in lowincome households across Africa and Asia, promises to expand telemedicine's reach. ${ }^{5}$ Providing neurologic care via telemedicine systems in humanitarian emergencies therefore may not need to be sophisticated to deliver benefit. There is also a substantial cost reduction associated with avoiding expensive referrals in regions where there is a chronic shortage of specialists. ${ }^{12}$ In this case, the neurologists are volunteering their time, making the service free.

Changing the patient's clinical course. In several cases, we were able to provide assistance in changing the diagnosis or management of patients. For example, one with traumatic brain injury (TBI) and post-TBI seizure was recommended to have an extended duration of an antiepileptic drug (AED) and lifelong therapy if seizures recurred with AED dose reduction. ${ }^{13}$ In a second patient, we added acyclovir and antibiotic coverage for methicillin-resistant Staphylococcus aureus to the antibiotic regimen of a persistently febrile child with seizures. In a 2013 article presenting perspectives of referrers and specialists using the MSF system, $91 \%$ of referrers found the consultations to be beneficial, stating that the consult clarified their diagnosis, assisted with management of the patient, and was educationally valuable. ${ }^{14}$ For physicians in the field who are working in highly stressful circumstances, an additional clinical sounding board can be critical.

Creating a community for referrer and specialist. The interest in global and humanitarian neurology is increasing among neurologists, ${ }^{15}$ and teleneurology offers an additional opportunity for the burgeoning field of global neurology. One of the benefits we have experienced is being able to identify and work with other physicians who share our interest in applying our neurologic expertise to resource-limited settings. Telemedicine has also been shown to help reduce the feeling of isolation of field doctors, ${ }^{16}$ as well as offering distance education for field health workers who otherwise have few opportunities to enhance their specialty knowledge and training.

PITFALLS AND CHALLENGES While there is great promise for the use of teleneurology in humanitarian contexts, several limitations remain.

Limited diagnostic resources and difficult decisionmaking. Even basic imaging and laboratory tests are often not available in humanitarian settings, making proposing appropriate recommendations difficult. When imaging is available, transferring this information with limited Internet access can be especially 
challenging due to low bandwidth Internet connections, although even in low bandwidth settings, photographs can be uploaded with considerable patience. Empiric treatment can be offered for syndromic presentations, but can pose potential adverse effects or toxicities, or create a cost burden. Generally speaking, there is a shift from the traditional approach of securing a final neurologic diagnosis - which in our experience occurred rarely-to a focus on neurologic disease categories and sinister and not-to-miss diagnoses and their treatments.

Further, clinicians in the field are not equipped or trained to provide answers even about the neurologic examination without a mastery of neurologic language, examination tools such as a reflex hammer, or confidence in performing a reliable neurologic examination. For the neurologist, this can contribute to a feeling of "shooting in the dark at a moving target." In a 2015 study of the MSF telemedicine experience assessing user feedback, $33 \%$ of specialists stated that the information supplied by the referrer was inadequate. ${ }^{17}$

Familiarity between the field site and the neurologist. The neurologist's understanding of individual site resources and local disease epidemiology is critical in informing appropriate clinical recommendations. For example, one patient's case was informed by an understanding of a measles outbreak in Democratic Republic of Congo. Further, Konzo-an irreversible, static, and symmetric myeloneuropathy associated with high dietary cyanogen intake from inadequately processed bitter cassava roots - can only be considered if the consultant is aware of whether cassava is part of the African diet where the case question originates. As cases from the same field site became more frequent, we found that our consultations also became more targeted as our awareness of the local disease burden and available resources increased. The telemedicine platform itself does not provide surveillance, epidemic, or epidemiologic resources to consultants. Therefore, they must be aware of available resources on outbreaks, regional disease risk, and vaccination and dietary patterns.

Gaps in US-based neurology education. The cases we saw included a substantial number of pediatric cases, tropical and other infectious diseases including vaccine-preventable diseases, and traumatic cases. These areas are often not well integrated in US curricula for neurology residents and fellows, or represent topical areas where residents and fellows have more limited clinical exposure. One of the authors (F.J.M.) obtained fellowship training in neuroimmunology and neurologic infectious diseases, as well as completing fieldwork in resource-limited settings abroad through a $\mathrm{PhD}$ in International Health, consultancies with the WHO, United Nations High Commissioner for Refugees, Polio Eradication Initiative, and refugee-centered nongovernmental organizations, focused in Africa, the Middle East, and Asia. The other author (A.S.) completed several international electives including in sub-Saharan Africa to bolster her knowledge of neurologic care in resource-limited settings. The MSF service itself provides no updated epidemic information data or outbreak or regional information. The authors are aware of and could thus readily access data via the Polio Eradication Initiative (polioeradication.org),

Eurosurveillance (eurosurveillance.org), and the CDC Yellowbook (cdc.gov/features/yellowbook/), among other relevant resources. US-based neurologists without an interest or experience in neurologic care in low- and middleincome countries may therefore be suboptimally positioned to provide meaningful advice.

Infrequent follow-up and feedback from the field. We found one of the limitations to the experience was absence of consistent patient follow-up information, which made it difficult to assess the outcome of our consultations. We received follow-up about a patient's progress in $30 \%$ of cases. In the cases for which we received feedback from the field physician (e.g., about the feasibility of our recommendations), we were able to improve our recommendations for future consultations, but this practice was not routine. In a survey of referrers and specialists using the MSF telemedicine platform, $45 \%$ stated that they had provided feedback about the patient to the specialist; however, $92 \%$ of the specialists reported not receiving any feedback about the patient. ${ }^{14}$ The MSF field environment, with rapid turnover of staff and patients often not returning after discharge, likely contributes to this lower referrer feedback.

Low frequency of consultations. In a period of approximately 1 year, we received only 10 consultations. We are among $>10$ neurologists listed in the MSF database, with 150 cases managed among the group. However, we suspect that the prevalence of people with neurologic diseases exceeds the 150 cases for which there were teleneurology consultations. In a retrospective analysis of neurologic diseases seen in 127 refugee camps monitored by the United Nations High Commissioner for Refugees, visits for sentinel neurologic diseases were in the range of thousands. ${ }^{18}$ Low uptake of the telemedicine service could be due to several reasons, including low promotion of the service at field sites, limited time, potential language barrier of the referring physician, or resource constraints at field sites preventing use of telemedicine services. With regards to neurologic questions in particular, we anticipate that most likely potential factors are a lack of recognition of neurologic issues or belief that limited resources affect what can actually be 
offered in the field. The staccato nature of consultsalthough seemingly positive on one hand, due to the low time commitment required on the neurologists' behalf — can also be difficult in that timely replies (typically within 24 hours) are required.

DISCUSSION Telemedicine can create access to, and reduce the cost of, specialty neurologic care by facilitating the provision of expertise at remote sites, particularly in resource-limited humanitarian settings, where there is a disproportionate burden of neurologic disease. ${ }^{2}$ Neurologists may be uncertain about the value they add in a humanitarian crisis, but our experience tells us we are at times critically needed and can make a significant impact. Of course, introducing any novel technology in health care comes with inevitable challenges, but an iterative process involving user feedback can lend itself to making the technology more affordable, available, and timely. The MSF experience highlights the need for improved resource availability for neurologic disorders in resource-limited settings, increasing familiarity of neurologists with the background of the country they are striving to serve, and the importance of follow-up and feedback as potential areas of growth for future teleneurology projects in humanitarian crises.

\section{AUTHOR CONTRIBUTIONS}

Dr. Saadi: design or conceptualization of study, analysis and interpretation of data, drafting or revising the manuscript. Dr. Mateen: design or conceptualization of study, study supervision, critical revision of manuscript for intellectual content.

\section{ACKNOWLEDGMENT}

The authors thank Professor Richard Wootton, University of Queensland, Australia, for feedback on the manuscript.

\section{STUDY FUNDING}

No targeted funding reported.

\section{DISCLOSURE}

The authors report no disclosures relevant to the manuscript. Go to Neurology.org for full disclosures.

\section{REFERENCES}

1. Mateen FJ. Neurological disorders in complex humanitarian emergencies and natural disasters. Ann Neurol 2010; 68:282-294.

2. World Health Organization \& World Federation of Neurology. Atlas: Country Resources for Neurological Disorders [online]. Geneva: World Health Organization; 2004. Available at: who.int/mental_health/neurology/ epidemiology/en/. Accessed June 15, 2016.
3. Mateen FJ, Clark SJ, Borzello M, et al. Neurology training in sub-Saharan Africa: a survey of people in training from 19 countries. Ann Neurol 2016;79:871-881.

4. Abimbola S, Malik AU, Mansoor GF. The final push for polio eradication: addressing the challenge of violence in Afghanistan, Pakistan, and Nigeria. PLoS Med 2013;10: e1001529.

5. Ericsson mobility report: on the pulse of the networked society. 2016. Available at: ericsson.com/assets/local/ mobility-report/documents/2016/ericsson-mobility-reportnovember-2016.pdf. Accessed March 8, 2017.

6. Médecins Sans Frontières. MSF Activities 2015 [online]. Available at: msf.org/en/msf-activities. Accessed June 19, 2016.

7. Global telemedicine market: growth, trends and forecasts (2015-2019). 2015. Available at: mordorintelligence.com/ industry-reports/global-telemedicine-market-industry. Accessed June 17, 2016.

8. Adler-Milstein J, Kvedar J, Bates DW. Telehealth among US hospitals: several factors, including state reimbursement and licensure policies, influence adoption. Health Aff 2014;33:207-215.

9. George BP, Scoglio NJ, Reminick JI, et al. Telemedicine in leading US neurology departments. Neurohospitalist 2012;2:123-128.

10. Dall TM, Storm MV, Chakrabarti R, et al. Supply and demand analysis of the current and future US neurology workforce. Neurology 2013;81:470-478.

11. Bonnardot L, Liu J, Wootton E, et al. The development of a multilingual tool for facilitating the primary-specialty care interface in low resource settings: the MSF teleexpertise system. Front Public Health 2014;2:126.

12. Wootton R, Bahaadinbeigy K, Hailey D. Estimating travel reduction associated with the use of telemedicine by patients and healthcare professionals: proposal for quantitative synthesis in a systematic review. BMC Health Serv Res 2011;11:185.

13. Chen JW, Ruff RL, Eavey R, et al. Posttraumatic epilepsy and treatment. J Rehabil Res Dev 2009;46:685-696.

14. Wootton R, Liu J, Bonnardot L, et al. Quality assurance of teleconsultations in a store-and-forward telemedicine network: obtaining patient follow-up data and user feedback. Front Public Health 2014;2:247.

15. Lyons JL, Coleman ME, Engstrom JW, Mateen FJ. International electives in neurology training: a survey of US and Canadian program directors. Neurology 2014;82:119-125.

16. Bagayoko CO, Perrin C, Gagnon MP, Geissbuhler A. Continuing distance education: a capacity-building tool for the de-isolation of care professionals and researchers. J Gen Intern Med 2013;28(suppl 3):666-670.

17. Bonnardot L, Wootton El, Liu J, et al. User feedback on the MSF tele-expertise service after a 4-year pilot trial: a comprehensive analysis. Front Public Health 2015;2:257.

18. Mateen FJ, Carone M, Haskew C, Spiegel P. Reportable neurologic diseases in refugee camps in 19 countries. Neurology 2012;79:937-940. 


\section{Neurology}

\section{International Issues: Teleneurology in humanitarian crises: Lessons from the Médecins Sans Frontières experience \\ Altaf Saadi and Farrah J. Mateen \\ Neurology 2017;89;e16-e19 \\ DOI 10.1212/WNL.0000000000004114}

\section{This information is current as of July 17, 2017}

Updated Information \& Services

References

Permissions \& Licensing

Reprints including high resolution figures, can be found at: http://n.neurology.org/content/89/3/e16.full

This article cites 13 articles, 4 of which you can access for free at: http://n.neurology.org/content/89/3/e16.full\#ref-list-1

Information about reproducing this article in parts (figures,tables) or in its entirety can be found online at:

http://www.neurology.org/about/about_the_journal\#permissions

Information about ordering reprints can be found online:

http://n.neurology.org/subscribers/advertise

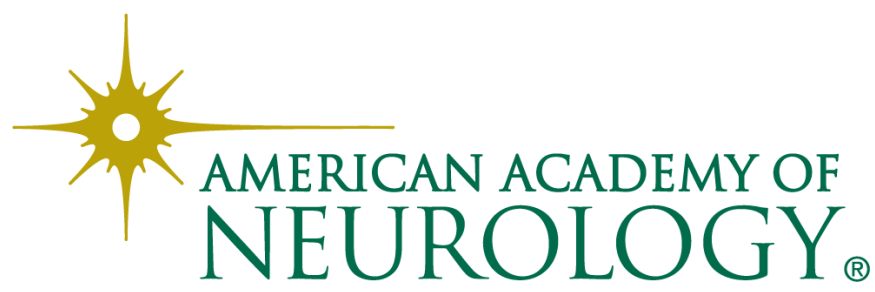

